\title{
Linguagem esquemática no cinema: uma abordagem analítica
}

\author{
Schematic language in movies: an analytical approach
}

cinema, elementos esquemáticos, configurações gráficas.

\begin{abstract}
O propósito deste artigo é evidenciar o uso da linguagem esquemática em filmes narrativos de longa metragem, predominantemente de ficção, produzidos em época recente. Mais especificamente, o objetivo é observar seus elementos, utilizando a classificação proposta por Aragão (2006), onde são definidas dez categorias sintáticas e semânticas presentes na literatura do design e do cinema. Três configurações gráficas cinematográficas de três filmes diferentes foram escolhidas: a trajetória de um suicídio de Magnólia (Paul Thomas Anderson, 1999), a partitura do último concerto de Tônica dominante (Lina Chamie, 2000) e o cenário de Dogville (Lars Von Trier, 2003). Nelas, os elementos esquemáticos possuem conteúdo informacional, ou seja, são determinantes na significação da configuração gráfica. Após as análises, apresentamos algumas considerações qualitativas acerca desses elementos no cinema, objetivando estabelecer algumas ligações entre as categorias e, principalmente, trazendo algumas questões para debate.
\end{abstract}

cinema, schematic elements, graphic configurations.

The purpose of this paper is to highlight the use of schematic language in recently produced dominantly narrative feature films. More specifically, the aim is to observe its elements by using the classification proposed by Aragão (2006), in which ten syntactic and semantic categories are defined, taking into account design and cinema theories. Three graphic cinematographic configurations of three different movies were chosen: the trajectory of a suicide in Magnolia (Paul Thomas Anderson, 1999), the musical score of the last concert in Tônica Dominante (Lina Chamie, 2000), and the scenario of Dogville (Lars Von Trier, 2003). In all scenes, the schematic elements carry informational contents, that is, they are dominant factors for the meaning of the graphic configuration. After the analysis, there follows some considerations regarding these elements in the movies, aiming to establish links between the categories and also raise certain questions for debate.

\section{Introdução}

A busca pela representação de imagem em movimento começa muito antes da fotografia. O longo caminho do cinema iniciou-se com os homens pré-históricos e seus desenhos seqüenciais em cavernas, passou pela invenção da câmara escura e da fotografia até chegar a vários aparatos pré-cinematográficos que tentavam sintetizar o movimento, como o fenaquisticópio. ${ }^{1}$ No entanto, o ser humano teve de evoluir significativamente para aprimorar a representação da imagem em movimento e, conseqüentemente, o cinema, através do seu desenvolvimento tecnológico. Em um século de existência, o cinema passou por várias transformações, desde a introdução da narração, a possibilidade do uso da cor e do som, até a utilização da tecnologia digital. Pode-se afirmar que o cinema ao qual estamos habituados, hoje em dia, diferencia-se totalmente das primeiras exibições cinematográficas.

\footnotetext{
* Universidade Federal do Pernambuco - UFPE

${ }^{1} \mathrm{O}$ fenaquisticópio, desenvolvido por Plateau, em 1832, foi o predecessor do cinematógrafo de Lumière. O movimento era visto por uma fenda de um disco, em que as imagens fixas eram colocadas nos raios e cuja rotação animava-as. (Machado, 1997, p.20).
} 


\section{Infodesıgn}

Podemos observar ao longo desses anos a pluralidade de matérias de expressão ${ }^{2}$ utilizadas pelos filmes para tecer sentido, ou seja, apesar de saber que o cinema foi desenvolvido com base em uma necessidade de representação visual do movimento, e, desde o início, críticos e cineastas atribuíram às palavras fílmicas um caráter não cinematográfico, uma inferioridade expressiva, logo cedo outros elementos, menções escritas e sons (Metz, 1980), também considerados fílmicos, estavam sendo utilizados concomitantemente às imagens.

\section{A dimensão gráfica do cinema}

A dimensão gráfica do cinema, em Aragão (2006), caracteriza-se na ampliação da matéria de expressão 'menção escrita' da linguagem cinematográfica definida por Metz (1980). Essa abordagem adota outra nomenclatura para os elementos gráficos utilizados nos filmes, 'configuração gráfica', e utiliza conceitos da linguagem gráfica, linguagem cinematográfica e narrativa para gerar dez categorias com o objetivo de propor uma classificação das configurações gráficas no cinema. Com essa abordagem, pretendemos dar conta de observar como elementos esquemáticos se apresentam nos filmes de maneira sintática e semântica.

A primeira categoria consiste em considerar os modos de simbolização, definidos por Twyman (1979), que compõem essas configurações. Nessa perspectiva, obtêm-se:

- Configurações gráficas verbais;

- Configurações gráficas pictóricas;

- Configurações gráficas esquemáticas - tudo o que não é nem verbal nem pictórico;

- Qualquer combinação destas três.

A segunda categoria distingue as configurações de acordo com a quantidade de elementos que as constituem e divide-se em:

- Configurações gráficas singulares - formadas por apenas um elemento;

- Configurações gráficas compostas - formadas por mais de um elemento.

As configurações gráficas compostas podem ser subdivididas de acordo com seus modos de simbolização. Aragão (2006) adaptou a variável 'consistência' de Ashwin (1979) para distinguir as configurações gráficas compostas, levando em consideração os tipos de elementos que as compõem. As configurações gráficas compostas podem ser formadas pelo mesmo tipo de elemento gráfico ou incluir diferentes categorias (verbal e pictórico, verbal e esquemático, esquemático e pictórico etc.). Desse modo, as configurações gráficas compostas podem ser:

- Configurações gráficas compostas homogêneas - todos os elementos são do mesmo modo de simbolização;

- Configurações gráficas compostas heterogêneas - elementos de diferentes modos de simbolização.

A quarta categoria das configurações gráficas da linguagem cinematográfica relaciona-as com a técnica de inserção nos filmes. Nesse caso, as configurações são divididas em:

- Configurações gráficas inseridas sobre as imagens filmadas;

- Configurações gráficas inseridas entre as imagens filmadas;

- Configurações gráficas inseridas no filme;

- Qualquer combinação destas três.

A quinta categoria consiste em dividir as configurações em relação à movimentação. Em vista disso, temos:

- Configurações gráficas estáticas;

- Configurações gráficas dinâmicas.

A sexta categoria concerne ao modo de obtenção das configurações. Portanto, existem:

\footnotetext{
${ }^{2}$ Metz ([1971] 1980) se baseou na noção de material de expressão desenvolvida por Hjelmslev ([1934] 1975) para propor uma síntese das matérias que o cinema utiliza para se expressar, definindo assim as bases físicas da linguagem cinematográfica. Segundo Metz ([1971] 1980, p.247), "o material da expressão é a natureza material (física, sensorial) do significante ou, mais exatamente, do 'tecido' no qual são recortados os significantes”.
} 
- Configurações gráficas mecânicas; e/ou

- Configurações gráficas manuais.

Antes de definir a sétima categoria das configurações gráficas do cinema, é necessário apresentar o conceito cinematográfico de diegese. Diegese é um termo associado à história, porém de amplitude maior, isto é, refere-se a "tudo aquilo que pertence, 'na inteligibilidade', à história narrada, ao mundo suposto ou proposto pela fiç̧ão do filme" (Souriau, 1953, p.7), então abrange a "história e seus circuitos" e o "universo fictício" que ele cria (Vanoye \& Goliot-Lété, 1994, p.40). Portanto, considerando as configurações gráficas de acordo com a diegese, obtêm-se três grupos:

- Configurações gráficas extradiegéticas - não pertencem ao espaço diegético;

- Configurações gráficas totalmente extradiegéticas - elas não pertencem ao universo diegético nem fornecem nenhuma indicação sobre a diegese em curso;

- Configurações gráficas intradiegéticas - pertencem ao espaço criado pelo filme.

A oitava categoria refere-se às configurações intradiegéticas, que são subdivididas em dois tipos levando em consideração a sua intencionalidade:

- Configurações gráficas intradiegéticas intencionais - intenção explícita de operar como representações gráficas, ou seja, de gerar significados propriamente gráficos.

- Configurações gráficas intradiegéticas casuais - captação aleatória da câmera.

Aragão (2006) utilizou as funcionalidades dos elementos na narrativa descritas por Barthes (1971) para definir a nona categoria. Logo, as configurações podem apenas narrar ou descrever fatos menos importantes que acontecem no filme ou podem ser pontos de articulação decisivos para o seguimento da história. Desta forma, temos:

- Configurações gráficas decisivas;

- Configurações gráficas secundárias.

Podemos perguntar, ainda, que porção de significação é atribuída aos elementos gráficos. As configurações gráficas, portanto, podem estar numa relação de redundância com outro elemento fílmico, isto é, não trazem informação nova à mensagem, assim como as configurações podem dividir com os outros elementos fílmicos do enunciado o sentido proposto na situação, além de poder significar de forma independente. Logo, podemos classificar as configurações gráficas de acordo com sua significação, relacionando-as com o conjunto dos elementos da seqüência para perceber se elas operam em simultaneidade ou de forma independente. Na décima e última categoria, temos:

- Configurações gráficas redundantes;

- Configurações gráficas complementares;

- Configurações gráficas autônomas.

Afora ser possível classificar as configurações gráficas cinematográficas, também se torna viável identificar semanticamente como os elementos que as compõem funcionam na comunicação. Engelhardt (2002, p.129) demonstrou que os elementos de uma configuração gráfica podem desempenhar diferentes papéis informacionais no que diz respeito a sua interpretação. Desse modo, propõe dividir os objetos gráficos - chamaremos de elementos gráficos -, que constituem as configurações, em: elementos informacionais, elementos referenciais e elementos decorativos.

Em Snatch - Porcos e diamantes, de Guy Ritchie (2000), além dos créditos, que informam os atores participantes do filme, existe uma seqüência em que são apresentados os personagens da história contada (Figura 1). Nesses exemplos aparecem elementos recorrentes que utilizaremos para designar os tipos de papéis informacionais definidos por Engelhardt (2002, p.129). 


\section{Infodesıgn}

Figura 1. Configurações gráficas com elementos informacionais, elementos referenciais e elementos decorativos em Snatch - Porcos e diamantes (Guy Ritchie, 2000).
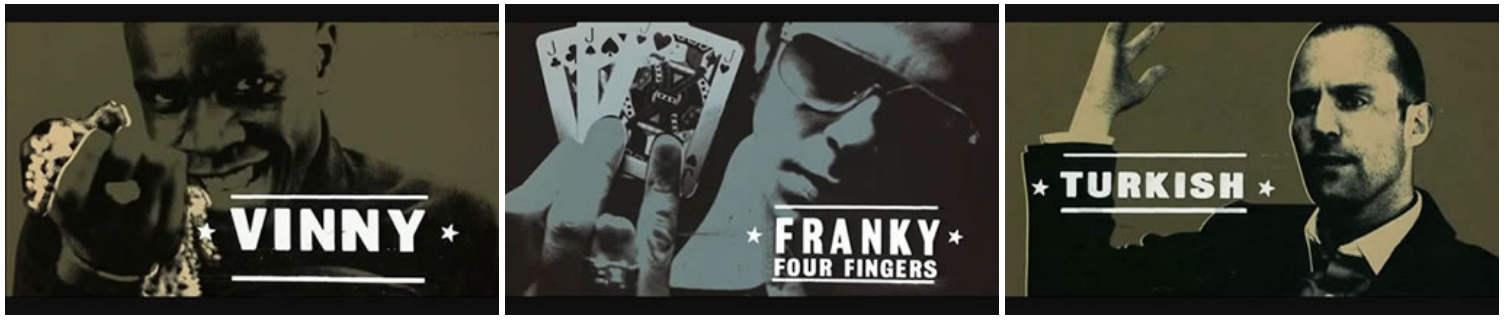

Os elementos informacionais são aqueles que devem ser modificados se a informação que se deseja passar for alterada. Exemplos de elementos informacionais são as áreas preenchidas num mapa que pretende informar as regiões com chuva, num certo dia. Em Snatch - Porcos e diamantes (Guy Ritchie, 2000), as palavras e a imagem que indicam o personagem, por exemplo, são elemento informacional, pois a configuração gráfica depende de qual personagem é apresentado.

Elementos referenciais são aqueles que servem para ajudar na interpretação da configuração e não, necessariamente, precisam ser ajustados se a informação representada mudar. Eles podem demarcar um espaço significativo na configuração, como eixos de um gráfico, linhas de grade, ou ainda funcionar como legenda quando explicam os símbolos ou as propriedades de uma configuração. É o caso das legendas de mapas que explicam as cores ou os símbolos utilizados.

As linhas dos planos de Snatch - Porcos e diamantes (Guy Ritchie, 2000) podem ser consideradas elementos gráficos esquemáticos referenciais, pois demarcam o espaço onde aparecerá o nome dos personagens. Elas mudam de posição para se encaixar melhor na composição do plano.

Os elementos decorativos não são nem informacionais, nem referenciais, e se forem retirados da configuração, não afetam a interpretação da informação intencionada. Servem para compor e não, obrigatoriamente, precisam estar relacionados com o contexto da configuração. Em alguns casos, um elemento que parece ser decorativo pode ser considerado informacional ou referencial, pois traz importante informação contextual. As estrelas dos planos de Snatch - Porcos e diamantes (Guy Ritchie, 2000) são consideradas decorativas, mas também poderiam ser classificadas como referenciais se a estrela fosse associada aos astros que participam da história.

Nem sempre uma mesma configuração gráfica apresentará elementos operando os três tipos de papéis aqui definidos. Aragão (2006) observou que configurações com elementos decorativos são raras no cinema. Na maioria das vezes, os elementos são informacionais e, em segundo plano, referenciais. Como nas seqüências do filme Anti-herói americano, de Shari Springer Berman e Robert Pulcini (2003), em que o texto é elemento informacional e o retângulo é elemento referencial (Figura 2).

Figura 2. Configurações gráficas com elementos informacionais e elementos referenciais em Anti-herói americano (Shari Springer Berman e Robert Pulcini, 2003).
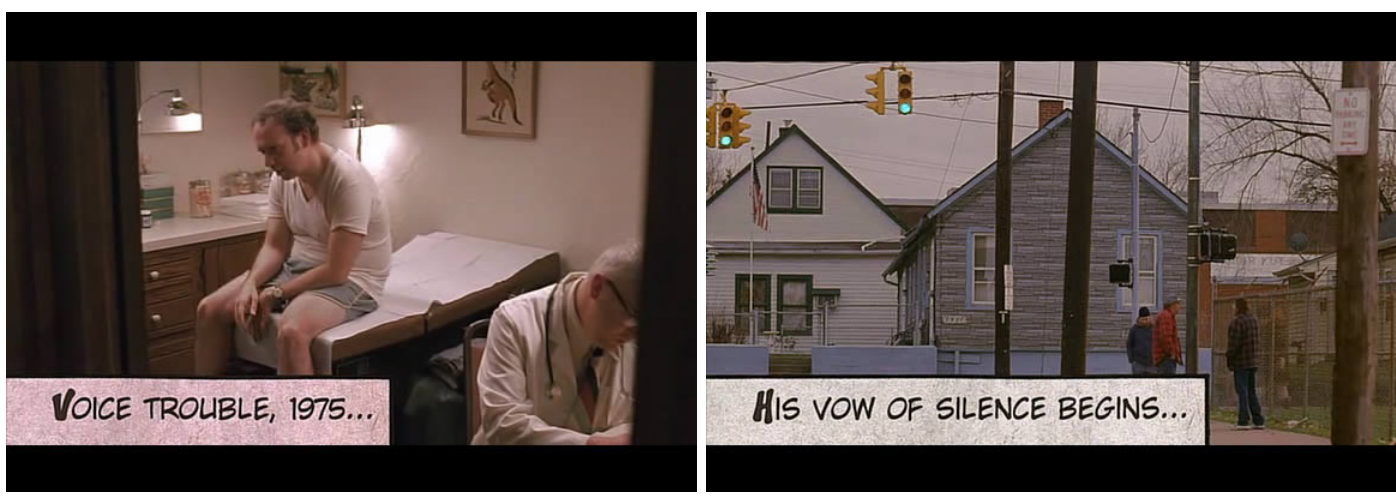

Engelhardt (2002, p.4) questiona se existe uma única linguagem visual para todas as configurações gráficas e propõe a noção de diferentes linguagens visuais, permitindo-nos distinguir a linguagem dos sinais de trânsito das linguagens dos mapas de metrô. Para esse autor, 
cada linguagem visual tem seu conjunto de regras de composição e um conjunto de constituintes gráficos com papéis sintáticos específicos.

Nos dois exemplos aqui apresentados, os elementos esquemáticos foram classificados como referenciais, e poderíamos pensar que esse tipo de elemento seja considerado apenas como referencial ou decorativo no cinema. No entanto, existem muitas configurações gráficas com elementos esquemáticos como conteúdo informacional. Os gráficos são configurações com linguagem visual própria, em que elementos esquemáticos têm papel referencial - no caso dos eixos $\mathrm{x}$ e $\mathrm{y}$, por exemplo - e informacional, pois o significado é mostrado por eles, através de retângulos, linhas etc.

Nos filmes também podemos observar elementos esquemáticos com papel informacional. Este artigo tem a intenção de verificar as possibilidades de representação da linguagem esquemática como meio de expressão fílmica. De forma qualitativa, examinaremos como esses elementos se comportam dentro da narrativa, à luz da classificação exposta anteriormente. Para isso,

observaremos três seqüências com elementos esquemáticos com papéis informacionais de filmes narrativos dominantes de longa metragem, predominantemente de ficção, produzidos na virada do milênio. São eles: Magnólia (P. T. Anderson, 1999), Tônica dominante (Lina Chamie, 2000) e Dogville (Lars Von Trier, 2003). Ao final da análise das três configurações, apresentamos um quadro que visa auxiliar na visualização de como as configurações escolhidas foram analisadas.

\section{Magnólia (Paul Thomas Anderson, 1999)}

Magnólia apresenta várias configurações gráficas durante as quase três horas de duração. Entre elas, a carta de um suicida, uma previsão do tempo e páginas que tratam sobre crianças superdotadas (Figura 3 ).

Figura 3. Exemplos de diferentes configurações gráficas em Magnólia (P. T. Anderson, 1999).
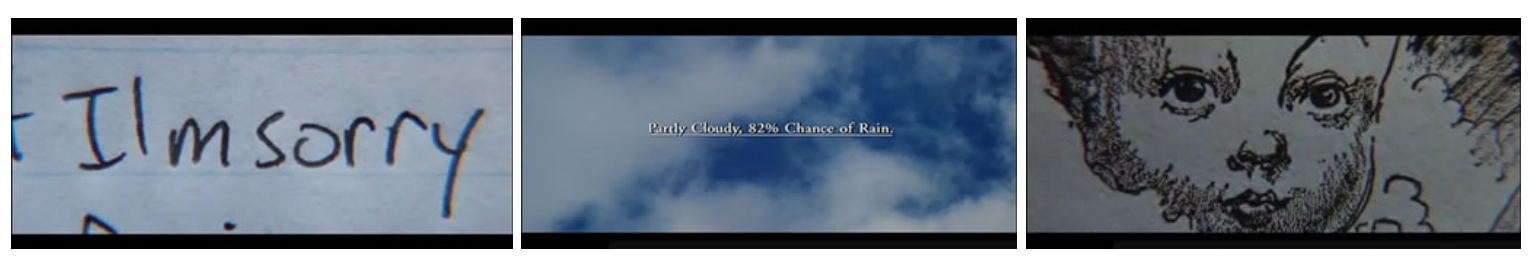

No entanto, nenhuma dessas se compara, em ineditismo, com a configuração gráfica esquemática sobreposta às imagens filmadas. A seqüência ocorre no começo do filme e narra a trajetória de um suicídio. Um jovem, Sydney Barringer, joga-se do alto de um edifício e é atingido por uma bala enquanto cai, esta disparada acidentalmente por sua mãe em ameaça a seu pai. Por conseqüência do tiro, ele morre antes mesmo de se chocar com o chão, ou melhor, de ser salvo por uma rede. Essa seqüência, além de ser narrada de forma verbal e mostrada visualmente pelas imagens filmadas, também é traçada na tela por elementos esquemáticos, como mostra a Figura 4.

Figura 4. Configuração gráfica esquemática em Magnólia (P. T. Anderson, 1999).
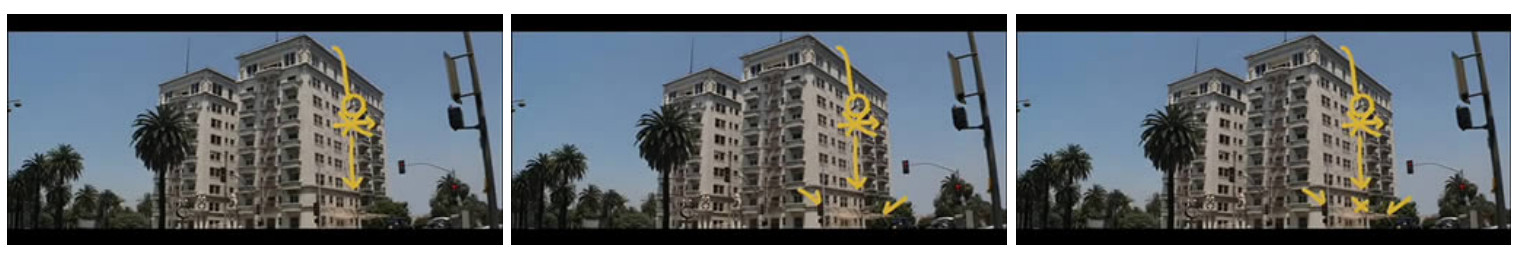

Como a locação das imagens filmadas não se modifica em toda a seqüência, que dura 23 segundos, somente o corpo se movimenta, e a atenção do espectador se dirige para as configurações gráficas. Neste exemplo, quem narra a trajetória visual do corpo e da bala são os elementos esquemáticos. A primeira ação é composta pelo homem se suicidando. A linha representa seu corpo caindo, um círculo aparece para indicar o local onde o personagem será atingido pelo tiro. A segunda ação não é mostrada pelas imagens filmadas, e sim descrita pelo narrador; fica implícita nesse plano, somente vemos a trajetória da bala e um ' $x$ ' para indicar que $o$ corpo foi atingido. O personagem continua sua queda, representada com uma linha na vertical $e$ uma seta. $E$, finalmente, setas que indicam a rede e outro ' $x$ ' para indicar a posição final de Sydney.

Antes de observarmos essa configuração, utilizando a classificação de Aragão (2006), é importante percebermos que o mesmo elemento gráfico, a seta, aqui elemento informacional, é 


\section{Infodesıg}

utilizado com significados diferentes. Horn (1998, p.159-160) definiu semântica funcional como o estudo das funções dos elementos da linguagem visual, ou seja, qual o propósito da inclusão de cada elemento nas configurações. As categorias da semântica funcional são determinadas através do arranjo e da tarefa de cada elemento da linguagem visual. Uma dessas categorias é "mostrar movimento" (Horn, 1998, p.171-172), que pode ser representada graficamente de várias maneiras, por exemplo, com linhas indicando o caminho do movimento ou setas que nos forçam a imaginar o deslocamento, como fizeram a linha e a seta na vertical da Figura 4.

As duas últimas setas na diagonal não estão sendo usadas para representar movimento, e sim para apontar o que estava sendo dito, ou melhor, para conectar a palavra (falada) com uma parte da imagem (mostrada). Novamente fazendo uma analogia com a semântica funcional de Horn (1998, p.173), essa configuração gráfica é utilizada para evidenciar a rede na imagem e se enquadra na função "mostrar o quê (nomear, legendar, indicar)", que normalmente integra elementos visuais e verbais.

Essa configuração gráfica é esquemática, pois é formada apenas por pontos, linhas, setas e círculos. É composta, já que se compõe por mais de um elemento, mas todos são do mesmo modo de simbolização. É, portanto, homogênea. Normalmente, elementos esquemáticos não são utilizados separadamente, no design gráfico, quando necessitam expressar uma mensagem precisa. Portanto, encontrá-los sobrepostos e, conseqüentemente, extradiegéticos às imagens filmadas é uma maneira de conjugá-los com outros elementos fílmicos. E, nesse caso, a configuração gráfica não se conecta somente com a banda visual do filme, está também numa relação de complemento com a narração e com os ruídos. Enquanto o narrador nos conta como aconteceu a morte de Sydney, vemos os elementos gráficos serem formados e informar, precisamente, em que local aconteceram tais ações. Fato que seria difícil acompanharmos somente através dos outros signos fílmicos. Por exemplo, o narrador diz que a briga dos pais ocorria três pisos abaixo do andar de onde Sydney saltou. Sem o ponto, a seta e o círculo que indicam essa ação, teríamos de contar as janelas do edifício para sabermos onde o personagem levou o tiro.

Os elementos da configuração gráfica não se movimentam, não se deslocam no espaço da tela cinematográfica, mas ela não pode ser considerada estática, pois seus elementos não são iguais no momento inicial e final em que aparecem. Eles surgem gradativamente, como se estivessem sendo feitos à mão, e são classificados como dinâmicos. A aparência manual da configuração, evidenciada pelos ruídos de giz numa lousa, produzidos numa situação de representação similar, não significa que ela tenha sido obtida manualmente, ou melhor, que ela tenha sido desenhada diretamente na película. Sabemos que os softwares da tecnologia digital têm ferramentas apropriadas para isso e que essa configuração gráfica deve ter sido gerada no computador, mas ela mantém as características estéticas necessárias para ser considerada manual.

Por fim, a configuração gráfica encontra-se antes mesmo de se iniciarem os créditos de abertura do filme, e não carrega informações decisivas para a narrativa, apenas se apresenta como configuração gráfica secundária, porém significativa para o entendimento da história.

\section{Tônica dominante (Lina Chamie, 2000)}

O filme de Lina Chamie narra três dias na vida de um clarinetista, seus envolvimentos e sentimentos com a música. O filme é repleto de configurações gráficas de partituras intra e extradiegéticas (sobrepostas e intercaladas), assim como textos escritos intercalados com as imagens (Figura 5).

Figura 5. Exemplos de configurações gráficas em Tônica dominante (Lina Chamie, 2000).
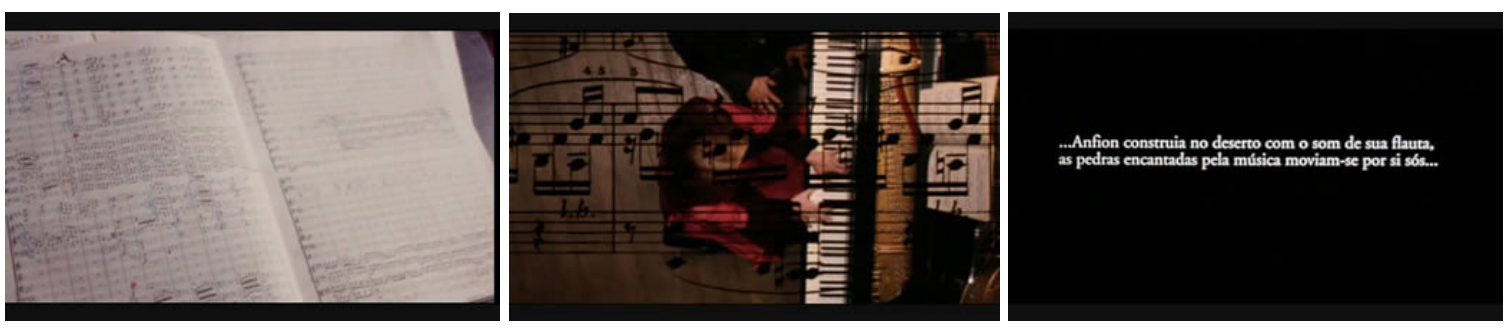

É importante mencionar, neste momento, que partitura de música não faz parte da linguagem gráfica verbal, LGV (Twyman, 1979), apesar de os símbolos da linguagem musical serem também convenções, como as letras de um alfabeto. No entanto, são consideradas como LGV apenas as 
línguas naturais e, conseqüentemente, sua representação escrita como configuração gráfica verbal.

Portanto, a seqüência escolhida do filme Tônica dominante (Lina Chamie, 2000) é uma composição de partituras apresentadas no ritmo da música tocada no concerto principal e final do filme (Figura 6). Como vimos anteriormente, as partituras são configurações gráficas esquemáticas mecânicas. Se tivesse algo escrito nelas, como em alguns momentos do filme, seriam verbais, esquemáticas, mecânicas e manuais. É composta homogênea, pois se configura por mais de um elemento do mesmo modo de simbolização. Em relação à funcionalidade desses elementos, os símbolos musicais são elementos informacionais, enquanto as linhas são elementos referenciais, pois ajudam na interpretação da mensagem, mas não precisam ser modificados se outra música estiver representada.

Figura 6. Configuração gráfica esquemática em Tônica dominante (Lina Chamie, 2000).
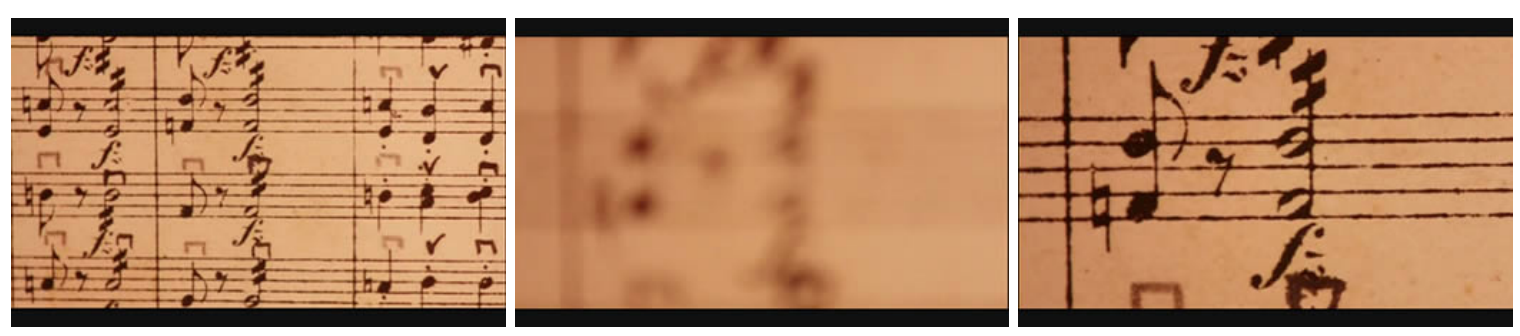

A configuração é composta, porém não é formada por objetos diferentes. Com um olhar mais detalhado e pausado sobre o filme percebemos que os planos são da mesma partitura, porém com enquadramentos distintos. No entanto, pode ser que os espectadores não tenham tempo suficiente para notar essa peculiaridade, numa sala de exibição, especialmente pelo dinamismo em que a seqüência é mostrada.

Podemos considerar a configuração gráfica como dinâmica. Mesmo que não aconteça um deslocamento perceptível das partituras, a mobilidade da configuração é evidenciada através da música, as notas musicais são exibidas no mesmo ritmo que a trilha sonora, numa seqüência de montagem e enquadramentos abertos e fechados, dependendo do tom em que a música é tocada. A passagem dos planos é feita com o desfoque da partitura sob o acompanhamento do fundo musical. Em vista disso, a configuração se complementa com a música para operar sentido. A configuração gráfica encontra-se no clímax do filme, em seu momento final e decisivo, porém a informação que ela carrega não pode ser considerada decisiva, pois não informa muita coisa ao espectador leigo, assim como outros planos associativos e plásticos relacionados ao concerto. Por conta disso, a configuração gráfica é considerada secundária.

A partitura não se encontra no filme, pelo menos não a vemos, então, diferentemente da música que é intradiegética, a configuração gráfica é extradiegética e se posiciona intercalada com as imagens filmadas.

\section{Dogville (Lars Von Trier, 2003)}

Em Dogville (Lars Von Trier, 2003), ao invés de filmar com cenário o diretor preferiu reduzir os elementos em cena: não existem casas, ruas, árvores e cachorros. Estes são representados através de formas geométricas e palavras.

O filme, que conta a chegada da personagem Grace à cidade de Dogville, apresenta ainda outras configurações gráficas (Figura 7), normalmente inseridas no filme, como as fotos dos cidadãos americanos no fim da exibição e o cartaz de 'Procura-se'. Como exceção, existem as aberturas de capítulos que dividem a história, posicionadas entre as imagens filmadas. 


\section{Infodesıgn}
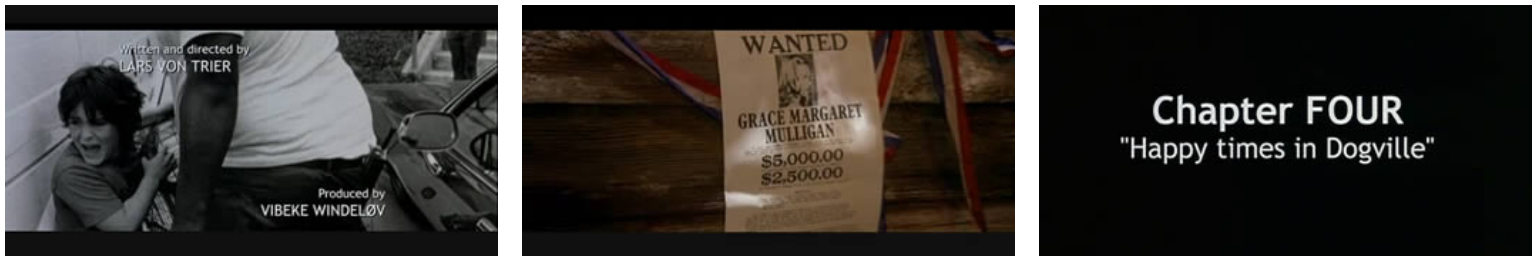

No entanto, o ineditismo do cenário, tanto para o design gráfico quanto para o cinema, faz que não seja escolhida uma cena em particular do filme, e, sim, toda a sua aparição durante a película. Logo no início, no prólogo, o narrador apresenta a cidade e seus personagens, vemos a configuração inteira num plano aberto de cima (Figura 8 ) e percebemos suas características.

Figura 8. Configuração gráfica verbal, pictórica e esquemática em Dogville (Lars Von Trier, 2003).

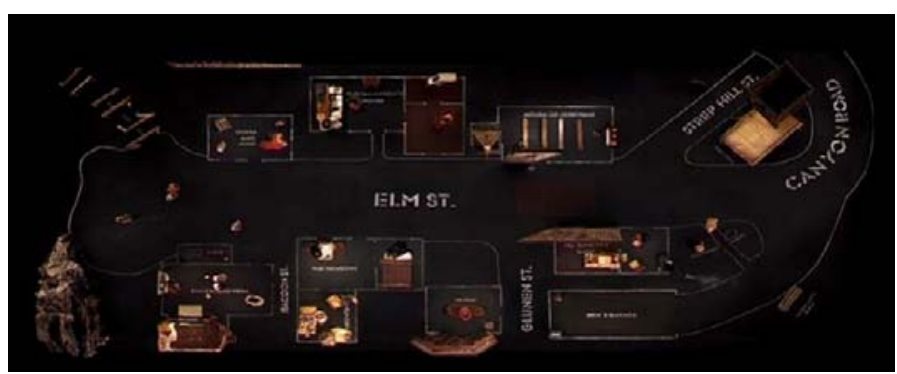

O cenário da cidade Dogville é considerado uma configuração gráfica de natureza verbal, pictórica e esquemática, pois apresenta, além das formas que definem a cidade, textos que descrevem ruas, casas e minas, e desenhos do cão e de árvores. Composta heterogênea por ser formada por mais de um elemento gráfico com modos de simbolização diferentes.

Também podemos considerá-la de natureza dinâmica, já que Aragão (2006) leva em consideração outros fatores, como formação dos elementos na seqüência ou uma junção de montagem e enquadramento, para distinguir as configurações em estática e dinâmica. Como configuração gráfica intradiegética e inserida no filme, ela poderia movimentar-se de duas maneiras: através do seu suporte, quando alguém folheia as páginas de uma revista, por exemplo, ou através da movimentação da câmera. Nesse caso, durante todo o filme vemos vários enquadramentos e movimentações de câmera diferentes.

Em relação ao modo de obtenção da configuração, características sintáticas do texto em estêncil e da cidade em giz fazem que seja classificada como manual, e, diferentemente de Magnólia (P. T. Anderson, 1999), ela pode ter sido realmente desenhada no chão.

Por ser intradiegética, temos que distingui-la em relação à sua intencionalidade. Como não estamos observando uma cena em particular, em que a configuração poderia ser considerada casual, e por ser tão atuante quanto os atores, o cenário é uma configuração gráfica intencional, com objetivos reais de informar localidade e espaço. Seus dados não narram fatos decisivos para a história, e, por conseqüência disso, ela é considerada uma configuração gráfica secundária que significa de forma complementar com os outros elementos fílmicos para informar a espacialidade da cidade, já que os personagens ainda têm que bater em portas invisíveis e não se vêem através de paredes inexistentes.

Os elementos esquemáticos dessa configuração são considerados informacionais, pois se a cidade fosse outra, ou se as casas tivessem outra posição ou tamanho, a representação teria de ser modificada.

\section{Reflexões}

A aplicação da classificação nessas configurações serve para demonstrar a diversidade de olhares que podemos empregar sobre a dimensão gráfica presente nos filmes. Portanto, com os exemplos deste artigo, verificamos o uso da linguagem gráfica esquemática como elemento significante nos filmes. Em outras palavras, os elementos esquemáticos estão sendo utilizados, com função informacional ou referencial, para ajudar os filmes a contar suas histórias, ampliando, desse modo, a função decorativa atribuída a alguns letreiros de filmes mudos, quando se utilizavam molduras feitas com linhas como em O Nascimento de uma nação, de David W. Griffith (1915). 
Os quadros seguintes auxiliam a visualização da presença da linguagem gráfica (em cada seqüência) à luz da classificação proposta por Aragão (2006). A classificação está dividida em categorias sintáticas (Quadro 1) e semânticas (Quadro 2).

Quadro 1. Representação visual das categorias sintáticas aplicadas às seqüências fílmicas.

\begin{tabular}{|c|c|c|c|c|c|}
\hline Categorias & $\begin{array}{l}\text { Modos de } \\
\text { simbolização }\end{array}$ & $\begin{array}{l}\text { Quantidade de } \\
\text { elementos }\end{array}$ & $\begin{array}{l}\text { Técnica de } \\
\text { inserção }\end{array}$ & Movimentação & $\begin{array}{l}\text { Modo de } \\
\text { obtenção }\end{array}$ \\
\hline Magnólia & \multicolumn{2}{|c|}{$\begin{array}{l}\text { Esquemática Composta } \\
\text { homogênea }\end{array}$} & Sobre Dinâmica & & Manual \\
\hline Tônica dominante & \multicolumn{2}{|c|}{$\begin{array}{l}\text { Esquemática Composta } \\
\text { homogênea }\end{array}$} & Entre Dinâmica & & Mecânica \\
\hline Dogville & $\begin{array}{l}\text { Verbal, Pictórica } \\
\text { e Esquemática }\end{array}$ & $\begin{array}{l}\text { Composta } \\
\text { heterogênea }\end{array}$ & No Dinâmica & & Manual \\
\hline
\end{tabular}

Quadro 2. Representação visual das categorias semânticas aplicadas às seqüências fílmicas.

\begin{tabular}{l|lll} 
Categorias & Diegese & $\begin{array}{c}\text { Importância da } \\
\text { informação }\end{array}$ & Significação \\
\hline Magnólia & Extradiegética Secundária & & Complementar \\
Tônica dominante & Extradiegética Secundária & & Complementar \\
Dogville & Intradiegética intencional & Secundária & Complementar \\
\hline
\end{tabular}

A análise dos dois quadros nos possibilita verificar algumas relações entre as categorias da classificação e nos estimula a refletir sobre o uso de certas combinações de configurações gráficas ou, no mínimo, instigar alguns questionamentos.

Ficou estabelecido que uma configuração gráfica composta necessita conter mais de um elemento gráfico. E, para ser 'composta homogênea', os elementos gráficos têm que ser do mesmo modo de simbolização; para ser 'composta heterogênea', os modos de simbolização têm de ser diferentes. Logo, podemos verificar uma relação direta entre utilizar vários modos de simbolização com a heterogeneidade (Dogville, Lars Von Trier, 2003) e utilizar um modo de simbolização com a homogeneidade (Magnólia, P. T. Anderson, 1999; e Tônica dominante, Lina Chamie, 2000).

A inserção das configurações tem uma relação direta com a diegese. Portanto, as configurações intercaladas e sobrepostas às imagens filmadas são mais comumente classificadas como extradiegéticas ou totalmente extradiegéticas. Já as inseridas no filme, somente podem ser intradiegéticas. No entanto, pode existir uma configuração inserida sobre o filme ou até mesmo intercalada, que seja considerada intradiegética, se acontecer a sua visualização antes da intercalação - por exemplo, se a partitura de Tônica dominante (Lina Chamie, 2000) estivesse inserida no filme. Isto é, se, de alguma forma, a configuração gráfica faz parte da diegese, e os espectadores possam perceber isso.

Algo interessante nessas três seqüências é que todas foram consideradas dinâmicas, diferentemente dos projetos de design gráfico em mídias estáticas, em que o dinamismo somente pode ser representado, por exemplo, com a utilização de repetição seqüenciada bidimensional ou com a utilização de elementos esquemáticos para indicar movimento. O cinema, uma mídia dinâmica por natureza, possibilita que os elementos gráficos da banda visual também se movimentem. Nessa perspectiva, observamos que as três seqüências utilizam a mobilidade do cinema de várias maneiras, para se tornarem dinâmicos.

As características manuais de duas das configurações analisadas demonstram que apesar de toda a tecnologia à disposição, os filmes estão interessados em apresentar as configurações de acordo com o que se pretende informar na cena, ou seja, mantêm as características manuais para contar fatos muitas vezes expressos pelo narrador, como se ele próprio estivesse fazendo a configuração enquanto nos conta a história, como em Magnólia (P. T. Anderson, 1999).

Em relação à importância da informação contida nas configurações gráficas e à significação, obtemos que as três seqüências foram consideradas como secundárias, por não trazerem informações que interfiram no desenrolar da narrativa, e também como complementares. Será que poderíamos afirmar que as configurações secundárias necessitam de outros elementos fílmicos para completar a significação? E, ainda, que configurações gráficas esquemáticas não conseguem ser de alguma forma decisivas e/ou autônomas num filme? Para respondermos a essas questões seria necessário examinar outros exemplos em profundidade. 


\section{Infodesıgn}

É importante ressaltar que a classificação das configurações em secundárias não significa que elas sejam dispensáveis ao filme. A conclusão que podemos obter é que os filmes analisados não utilizaram elementos gráficos esquemáticos com mensagens decisivas nas suas histórias. Mesmo assim, tais configurações estão numa relação de complementaridade com os outros elementos fílmicos, para gerar sentido. As configurações gráficas informam, porém não atuam com mensagens decisivas. Temos de levar em consideração que nem tudo num filme é decisivo, e somente poderíamos considerar as configurações gráficas como dispensáveis na mesma medida em que considerássemos dispensáveis outros elementos fílmicos que também têm mensagens secundárias.

Assim como em certas configurações gráficas do design gráfico, observamos com nossos exemplos que a linguagem gráfica esquemática também se encontra representada no cinema. Nos filmes, seus elementos podem ter diferentes características sintáticas e semânticas, ajudando, de alguma forma, os filmes a narrar suas histórias, do mesmo modo como o fazem as imagens em movimento e o som.

\section{Referências}

Aragão, I. R. 2006. A dimensão gráfica do cinema: uma proposta de classificação de suas configurações. Dissertação (Mestrado) - Departamento de Design, Universidade Federal de Pernambuco, Recife.

Ashwin, C. 1979. The ingredients of style in contemporary illustration: A case study. Information Design Journal, v.1, n.1:51-67.

Barthes, R. 1971. Introdução a análise estrutural da narrativa. In: Greimas, A. J. et al. Análise estrutural da narrativa. Trad. Maria Zélia Barbosa Pinto. 4.ed. Petrópolis: Vozes. p.19-60.

Engelhardt, Y. 2002. The language of graphics: a framework for the analysis of syntax and meaning in maps, charts and diagrams. Amsterdam: ILLC.

Horn, R. E. 1998. Visual language: global communication for the $21^{\text {st }}$ century. Bainbridge Island, Washington: Macrovu.

Machado, A. 1997. Pré-cinemas \& pós-cinemas. São Paulo: Papirus.

Metz, C. 1980. Linguagem e cinema. Trad. Marilda Pereira. São Paulo: Perspectiva.

Souriau, E. 1953. L'univers filmique. Paris: Flammarion.

Twyman, M. 1979. A schema for the study of graphic language. In: Kolers, P. A.; Wrolstad, M. E. \& Bouma, H. (Ed.). Processing of visible language. New York: Plenum Press, v.1:117-150.

Vanoye, F. \& Goliot-Lété, A. 1994. Ensaio sobre a análise fílmica. Trad. Marina Appenzeller. São Paulo: Papirus.

\section{Sobre as autoras}

\section{Isabella R. Aragão}

Mestre, Universidade Federal de Pernambuco; bacharel em Desenho Industrial - Programação Visual pela Universidade Federal de Pernambuco (2001); mestre em Design pela mesma instituição (2006). Atualmente é professora assistente do Departamento de Design da UFPE.

isabella.aragao@gmail.com 


\section{Solange G. Coutinho}

Doutora, Universidade Federal de Pernambuco; doutora em Typography \& Graphic

Communication - University of Reading (1998). Atualmente é professora adjunta da UFPE, membro associado do CRICC - Centre de Recherche Image, Cognition et Culture da Université

Paris 1 - Pantheon-Sorbonne; Pró-Reitora de Extensão da UFPE; Líder do Grupo de Pesquisa em Design da Informação/CNPq desde 2001.

solangecoutinho@globo.com 